\title{
Design com foco na redução dos resíduos sólidos: um estudo de caso em malharia retilínea
}

Design focusing on the reduction of solid waste: a case study in knitwear straight

\section{Ana Paula Gentile} Mestranda em Têxtil e Moda pela Universidade de São Paulo -USP paula.trico@usp.br

\section{Rita de Cássia Lopes Moro} Mestranda em Têxtil e Moda pela Universidade de São Paulo - USP claudias@feevale.br

Francisca Dantas Mendes Professora Dra. de Têxtil e Moda pela Universidade de São Paulo - USP franciscadm.tita@usp.br 


\section{Design com foco na redução dos resíduos sólidos: um estudo de caso em malharia retilínea}

Design focusing on the reduction of solid waste: a case study in knitwear straight

Ana Paula Gentile, Rita de Cássia Lopes Moro e Francisca Dantas Mendes

\section{Resumo}

As questões que permeiam a sustentabilidade estão cada vez mais presentes no cotidiano das pessoas, notadamente na indústria da moda. A problemática dos resíduos sólidos desafia empresas, governo e sociedade a elaborar estratégias para sua redução e eliminação. Diante da crescente preocupação e representatividade que os setores têxtil e de confecção possuem nos âmbitos nacional e internacional, o presente artigo se propõe a somar como referencial bibliográfico apresentando um caso real. O estudo busca a elucidação de técnicas focadas na estratégia de design diferenciado visando a redução e eliminação de resíduos têxteis na malharia retilínea.

Palavras- chave: Malharia retilínea, Resíduos Sólidos, Moda.

\begin{abstract}
The issues that permeate sustainability are increasingly present in daily life, no different in the fashion industry. Within these interrogative, it is the issue of solid waste, which challenges business, government and society to develop strategies for their reduction and elimination. Thus, in view of the growing concern and representatively that the textile and apparel sector has, at national and international level, this article comes to add as bibliographic references, and by presenting real case, seeking clarity on, focused on strategy distinctive design, aimed at reduction and elimination of textile waste in rectilinear knitting.
\end{abstract}

Keywords: Rectilinear knitting, Solid Waste, Fashion. 


\section{Introdução}

Muitos dos problemas ambientais acontecem devido a intervenções cada vez mais invasivas realizadas pelo homem. A questão no momento é como podemos continuar usufruindo do ambiente natural sem destruir o meio ambiente (DIAS, 2014). Vive-se um consumo crescente referente à exploração dos recursos naturais e isso ocorre devido a um crescimento tanto populacional quanto industrial. Questões ambientais devem estar inseridas sempre nas decisões empresariais (MILAN; REIS; VITORAZZI, 2010; IPEA, 2012).

Praticar um desenvolvimento sustentável não é simplesmente manter os recursos naturais. Deve-se considerar o desenvolvimento do produto associando inovações tecnológicas, produções limpas e outros recursos que possam acrescentar melhorias de produção visando a sustentabilidade (DIAS, 2014).

A problemática gerada pelos resíduos sólidos não ocorre apenas em função da sua geração, mas do correto estudo e entendimento sobre as questões que os norteiam. Os impactos causados pelo descarte incorreto podem poluir tanto o solo, como a água e o ar, desencadeando uma série de consequências nocivas nos pilares da sustentabilidade: ambiental, social e econômica.

Nesse sentindo, Fletcher e Grose (2011) chamam atenção para os processos de reutilização, restauração e reciclagem com o objetivo de interceptar resíduos têxteis destinados aos aterros sanitários, conduzindo-os de volta ao processo produtivo na forma de matérias-primas. Alertam para a necessidade de reformulação do design, estratégias de coleta e engenharia de negócios, buscando sempre fazer melhor uso dos recursos inerentes ao produto antes de projetá-los e descartá-los.

No cenário brasileiro os setores têxtil e de confecção, como demonstram os dados do IEMI (2014), estão em quinto e quarto lugares entre os produtores mundiais respectivamente, sendo considerados importantes desenvolvedores socioeconômico do país (MORO; MENDES, 2014). A produção específica de tecidos de malha retilínea também possui grande relevância no cenário contando com 13.373 empresas formais e informais, conforme dados do SEBRAE (2012, apud Piccinini; Mendes, 2014), em sua maioria de pequeno porte, gerando renda e emprego a milhares de brasileiros (ROSS, 2001).

Com o crescente aumento de geração de resíduos sólidos em escala mundial e diante da obsolescência dos produtos de moda, surge a preocupação em otimizar o uso da matéria prima 
e dos insumos empregando tecnologias e novos desenvolvimentos para possibilitar a redução de resíduos gerados. Como reduzir os resíduos gerados na malharia retilínea? A presente pesquisa procura respostas e faz parte dos estudos centrados nos aspectos socioambientais da indústria têxtil e de confecção com foco nos artigos de moda. O grupo de estudo está registrado no $\mathrm{CNPq}$ "Moda na Cadeia Têxtil" e, por meio de uma pesquisa bibliográfica e estudo de caso, aborda as principais inovações tecnológicas e técnicas aplicadas para redução dos resíduos sólidos têxteis.

\section{Referencial teórico}

Esta seção apresenta as pesquisas bibliográficas realizadas pelas autoras para proporcionar maior proximidade e conhecimento em relação ao tema estudado.

\section{Malharia retilínea: definição, produção e cenário}

Segundo Callan (2005), a malharia é a arte ou indústria de malhas (tricô) que tem por finalidade produzir tecido de malha, no qual se origina um tecido feito por cabos (fios) a partir das fibras naturais, artificiais e sintéticas.

As máquinas retilíneas se caracterizam pelo uso de agulha de lingueta no qual se nomeiam três partes, lingueta, cabeça e pé. As categorias desse tipo de maquinário são duas: as que utilizam um só conjunto de agulhas de lingueta chamada de monofrontura, responsáveis pela fabricação de tecidos simples em meia malha; e as que utilizam dois conjuntos de agulhas de lingueta opostas, conhecidas como dupla frontura, que produzem malha dupla e várias outras estruturas complexas (SISSONS, 2012).

Os tipos de máquinas se diferenciam também conforme a tecnologia empregada, podendo ser máquinas manuais, motorizadas, semiautomáticas e automáticas. O tipo de máquina a ser utilizada para a confecção do artigo interfere no processo produtivo, conforme mostra a figura 1, que apresenta o fluxograma das etapas do processo produtivo de uma meia malha com o emprego de máquinas de malharia retilínea.

Figura 1 - Fluxograma dos diferentes processos e etapas produtivas de malharia retilínea 


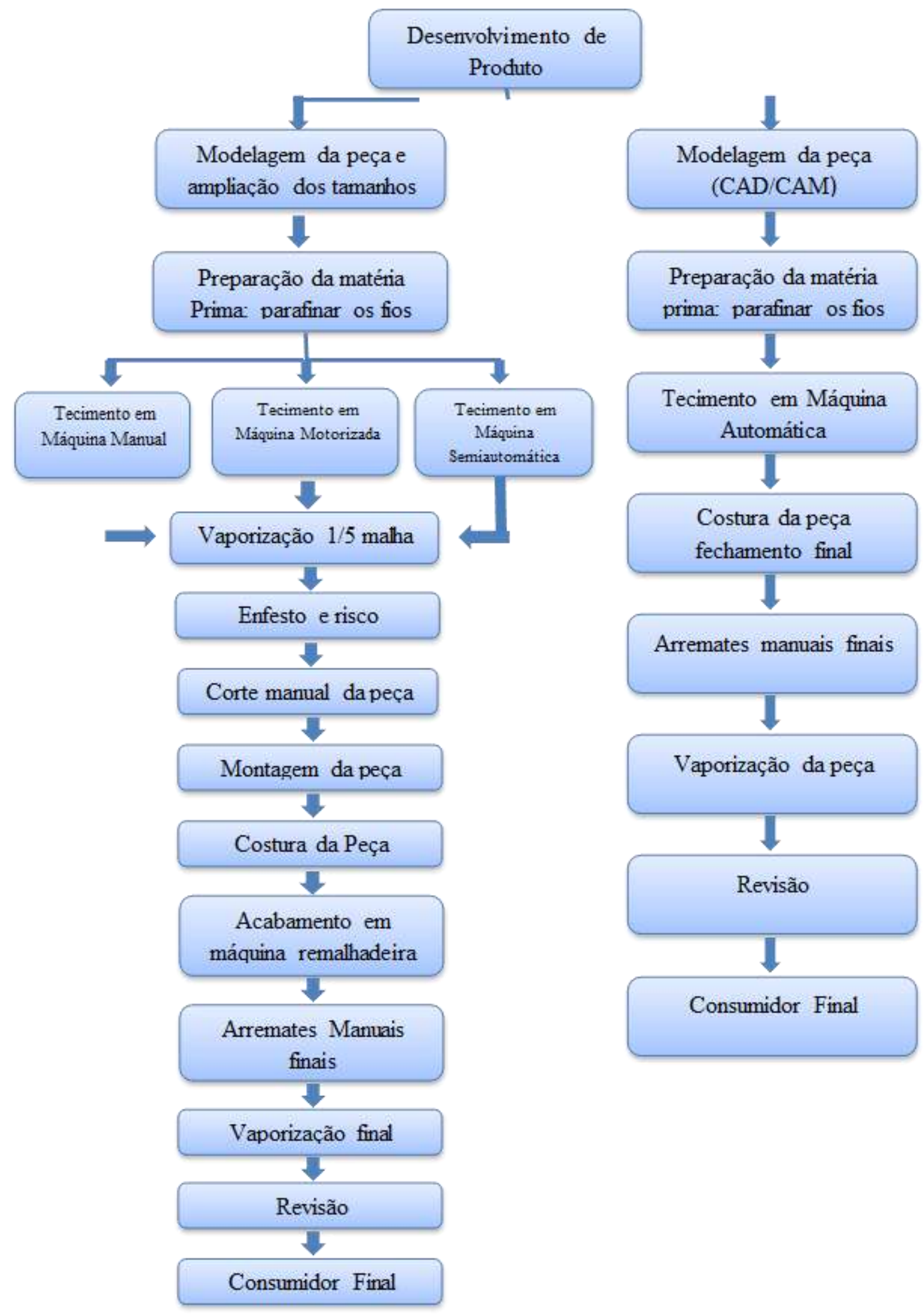

Fonte: Elaborado pelas autoras 
As máquinas industriais manuais são também denominadas como frontura em "V" porque possuem duas fronturas fixas e são consideradas de muita versatilidade, uma vez que o operador pode controlar todo o seu manuseio modificando pontos, velocidade e materiais, sendo mais direcionadas para vestuário de baixa produção e peças personalizadas. Já as máquinas motorizadas ganham um motor acoplado, possibilitando um maior rendimento em relação à manual, porém ainda dependendo das operações de alterações realizadas manualmente pelo operador. As máquinas semiautomáticas contribuem para uma maior produção, mas há ainda uma parte da programação manipulada pelo operador. Por fim, as automáticas, aliadas à tecnologia, ganham mercado e oferecem grande produtividade otimizando tempo em operações e em matérias primas.

Ross (2001) acrescenta que as automáticas ou teares retilíneos eletrônicos são equipamentos que possuem carros que se movimentam em alta velocidade com numerosas agulhas comandadas eletronicamente. As operações de tecimento são elaboradas com a utilização de um software instalado em um microcomputador a partir de informações como tipo de agulha, dimensões das peças, etc.

As máquinas eletrônicas do fully-fashion que obtém artigos semiacabados, tendem a diminuir ainda mais a geração de resíduos gerados, pois eliminam as operações de corte e montagem das peças (ROSS, 2001). No Brasil são muito utilizados os teares manuais para a produção em pequena escala e com maior possibilidade de geração de resíduos sólidos. A tabela 1 apresenta a quantidade e a média de anos de máquinas de malharia retilínea.

Tabela 1 - Parque de Máquinas Têxteis

\begin{tabular}{|l|l|l|l|}
\hline Máquinas Retilíneas & 1990 & 1999 & 2007 \\
\hline Número de máquinas & 36.613 & 36.175 & 39.765 \\
\hline Idade média (anos) & 10,3 & 4,4 & 10,7 \\
\hline
\end{tabular}

Fonte: Adaptado pelas autoras de COSTA; ROCHA (2009).

Ross (2001) concluiu que no cluster de Caxias do Sul no estado do Rio Grande do Sul, suas pesquisas apontaram que $77 \%$ das empresas utilizavam máquinas eletrônicas importadas adquiridas a partir da década de 90 e que os artigos de malha retilínea são sazonais, com tempo de vida de aproximadamente 6 meses. Esses dados, porém, não podem ser generalizados, uma vez que o setor estudado se refere apenas a um dos principais clusters brasileiro. É importante que análises sejam realizadas em empresas que ainda utilizam maquinários não automáticos, geradores de mais resíduos. 


\section{Resíduos sólidos têxteis}

A geração de resíduos sólidos é um tipo de poluição com graves consequências socioambientais. Abramovay (2009) afirma que a ineficiência do processo é uma forma de lixo econômico e não uma externalidade que decorre de maneira inevitável do processo produtivo.

Porter e Linde (1995) asseveram que nos últimos anos entidades reguladoras e empresas mais conscientes adotaram o conceito de prevenção da poluição, ou redução das fontes, que limita a poluição antes de sua ocorrência, aumentam a competitividade, geram menor impacto e apresentam melhores características. Essas empresas são pioneiras em inovação e desfrutam por muito tempo essas vantagens.

A cadeia têxtil gera um grande volume de poluentes em todas as etapas produtivas, nos processos de conservação das roupas com o uso de produtos químicos nas máquinas domésticas e no descarte final dos artigos. È forte o impacto ambiental, o que justifica uma detalhada investigação e esforços para possíveis soluções (ANICET et al, 2014).

Os dados sobre a geração e reciclagem dos resíduos têxteis no Brasil ainda são escassos e de difícil mensuração. Esse problema não é especifico do setor têxtil, como mostra o Diagnóstico de Resíduos Sólidos Industriais, elaborado pelo IPEA em 2012. Segundo o documento os dados obtidos pela pesquisa não permitiram um diagnóstico completo, pois alguns estados ainda não fizeram o inventário e os que o fizeram não possuem uma padronização adotando diferentes anos bases e poucas empresas inventariadas. A tabela 2 apresenta os dados dos estados que fizeram o inventário, mensurando os resíduos industriais têxteis:

Tabela 2 - Distribuição da quantidade de resíduos têxteis inventariada no Brasil

\begin{tabular}{l|c|c}
\hline Estado & Ano do Inventário & $\begin{array}{l}\text { Quantidade } \\
\text { Industriais Têxteis (ton.) }\end{array}$ \\
\hline Pernambuco & 2001 & $3.335,18$ \\
\hline Rio Grande do Sul & 2002 & $2.951,28$ \\
\hline Amapá & $2005-2007$ & 2,79 \\
\hline Ceará & 2001 & $8.017,03$ \\
\hline Minas Gerais & 2013 & $45.307,96$ \\
\hline Paraná & $2004-2009$ & $72.125,23$ \\
\hline Amazonas & 2012 & 20,03 \\
\hline
\end{tabular}

Fonte: Elaborado pelas autoras com base nos dados do IPEA (2012) e do Relatório de Resíduos Industriais do Estado de Amazonas (2012). 
Dados do SINDITÊXTIL (2009) apontam que a região do Bom Retiro e Brás em São Paulo são responsáveis por aproximadamente 12 e 10 toneladas/dia de resíduos sólidos têxteis respectivamente. Lopes (2013), em seus estudos, assegura que a quantidade de resíduos sólidos têxteis gerados na região do Bom Retiro "representa cerca de $2 \%$ dos resíduos produzidos no Brasil, cuja estimativa é da ordem de 175 mil toneladas/ano”. Já no Reino Unido, Gwilt (2014), aponta que cerca de 2,35 milhões de resíduos têxteis são desperdiçados por ano, sendo que $74 \%$ são enviados aos aterros sanitários e $26 \%$ para incineração.

Um dos principais fatores desencadeantes dessa problemática, segundo Berlim (2012), é devido ao curto ciclo de vida dos produtos de moda, sua instabilidade e às suas próprias características. Mendes (2010) salienta que a obsolescência é uma marcante característica e atende tendências de moda preestabelecidas.

Fletcher e Grose (2011) e Gwilt (2014) chamam atenção para o desenvolvimento de produto e apontam, como alternativas, além da conscientização por meio da educação ambiental para todos, a reorientação do design voltado para a geração de valor, proporcionando o oferecimento de artigos com vida útil prolongada, possível de reutilizar, remanufaturar, reciclar e, entre outras, o uso da técnica upcycling.

O upcycling permite um maior reaproveitamento do uso de materiais, prolongando sua vida e aumentando o valor do material. A técnica pode ser aplicada em produtos novos ou não, agregando valor por meio de pequenas alterações ou pela construção de um novo artigo utilizando sobras (FLETCHER; GROSE, 2011; GWILT, 2014). Essa técnica "oferece aos designers um número sem fim de oportunidades", conforme assevera (GWILT, 2014, p. 146).

Essas alternativas somam-se com o princípio da Lei 12.305 de 2010 - Política Nacional dos Resíduos Sólidos, instituída no Brasil que, conforme Torres e Borger (2014), aborda os princípios, objetivos, instrumentos e diretrizes para a gestão de uma forma geral. No núcleo de seus principais objetivos merece destaque: a diminuição da quantidade de descarte em aterros sanitários; economia de energia; preservação de recursos naturais; obtenção de vantagem econômica com a valorização dos resíduos. Quanto à perspectiva de prioridades, destacam-se a não geração, redução, reutilização, reciclagem e tratamento dos resíduos, disposição final ambientalmente adequada e reponsabilidade compartilhada (SILVA; LEITÃO; LEMOS, 2014). 
Além das contribuições e ações sociais e ambientais responsáveis, o resultado é economicamente viável, pois os ganhos decorrentes da prevenção na fonte e na reciclagem se dão tanto no processo, quanto nos produtos, tendo como economias: matéria prima; melhor utilização dos subprodutos; geração de valor; menor consumo de energia; redução nos custos; redução nos custos de embalagem; maior eficiência dos recursos; maior reaproveitamento da energia colorífica e redução na geração de efluentes (PORTER; LINDE, 1995; AZZONE; BERTELLÉ; NOCI, 1997; IPEA, 2012).

\section{Moda sob o viés da sustentabilidade: foco no design}

O aumento da importância de padrões sustentáveis tem levado as empresas a considerá-los como parte integrante da estratégia de negócios, implantando metas possíveis de serem alcançadas de forma a não comprometer a sociedade e o ambiente, conferindo lucratividade com inovação e sustentabilidade caminhando juntas (PINSKY; DIAS, 2014).

Para criação de um valor sustentável, segundo Hart e Milstein (2004), as empresas devem, além de ter foco na sua necessidade de criação de negócios e tecnologias, também nas ações de proteção de suas habilidades internas, procurando integrar conhecimentos vindos de fora, impulsionados por motivadores internos e externo dentro de uma perspectiva momentânea e futura.

A cadeia da indústria têxtil dentro de sua complexidade estrutural e organizacional, envolvendo inúmeras etapas até a obtenção final do produto, é um setor onde ainda se consome muita energia gerando resíduos, emissões atmosféricas, poluição de rios e solos.

A figura 2, apresenta o fluxograma das atividades da cadeia de suprimentos e o sentido do fluxo das informações. 
Figura 2 - Atividades da cadeia de suprimentos e fluxo das informações

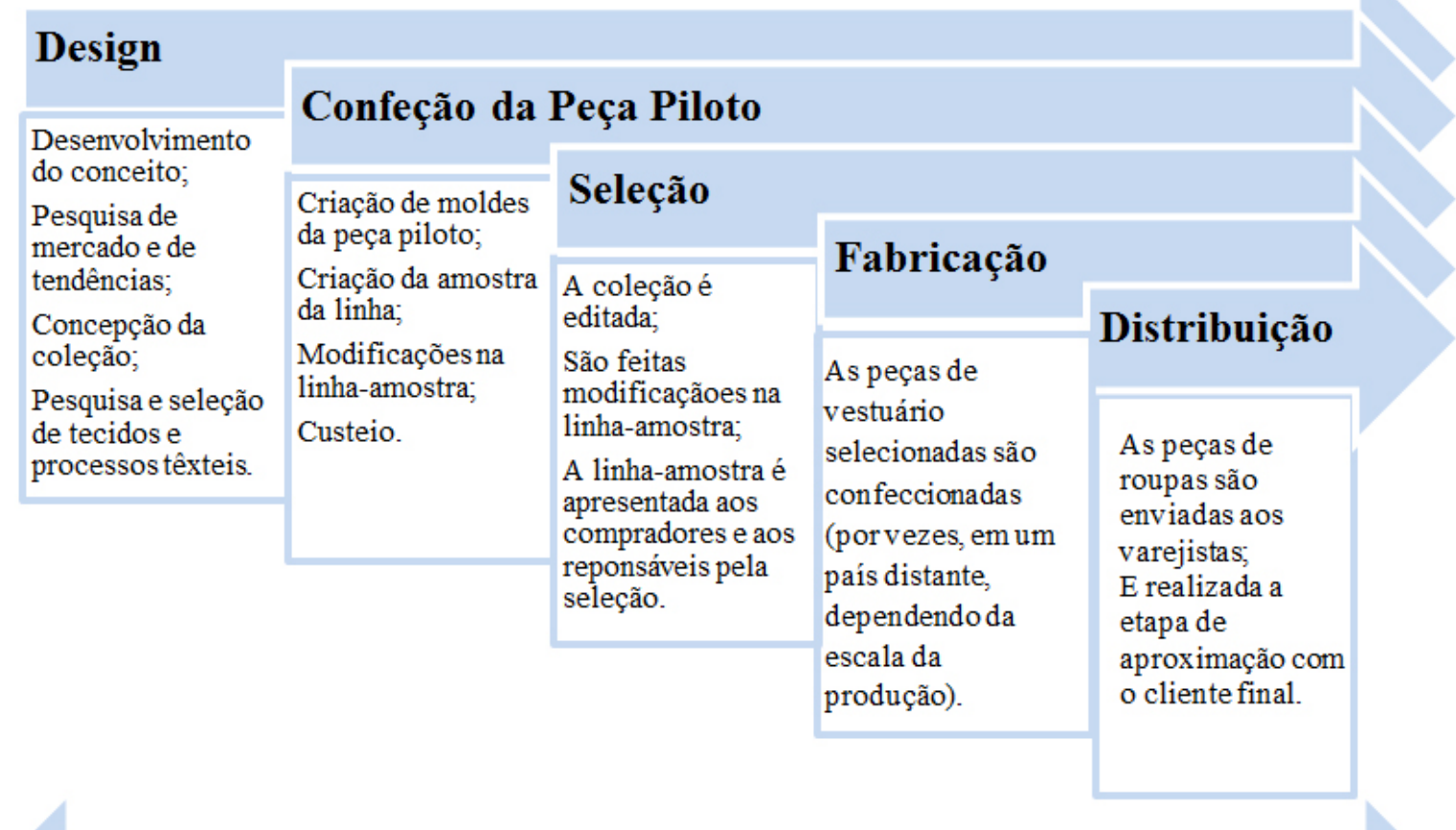

\section{Fluxo das informações}

Fonte: Adaptado pelas autoras de GWILT (2014, p. 15).

Nas figuras 2 e 3 o design está à frente da cadeia e no centro e age como impulsionador de novas ideias, novos materiais, processos produtivos, métodos de reaproveitamento, etc. É possível haver mudanças de padrões e promoção da conscientização por todos os elos da cadeia de valor (FLETCHER; GROSE, 2011; GWILT, 2014). 
Figura 3 - Uso de estratégias de design sustentável

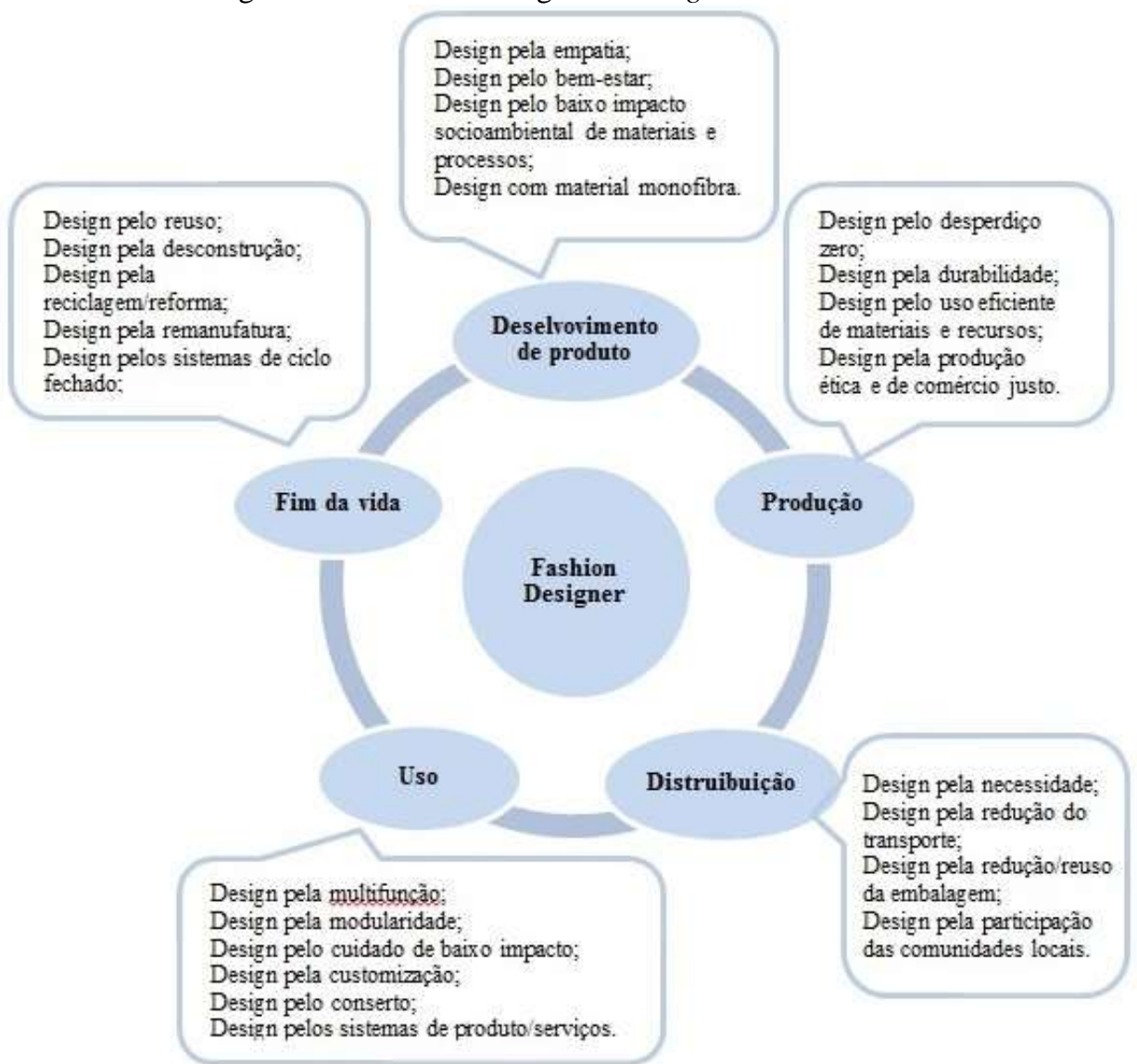

Fonte: Adaptado pelas autoras de GWILT (2014, p.43).

O designer não deve pensar somente no produto em si, mas no ciclo todo, como na durabilidade, na redução das partes, no papel do usuário, na desmontagem, entre outros, como se observa na figura 4. O designer deve pensar holística e ciclicamente, transitando por todos os elos da cadeia e transmitindo o desejo do consumidor que está embutido na peça. Deve ainda pensar nas mensagens de conscientização e educação para a sustentabilidade. 
Figura 4 - Estratégia de design para a sustentabilidade

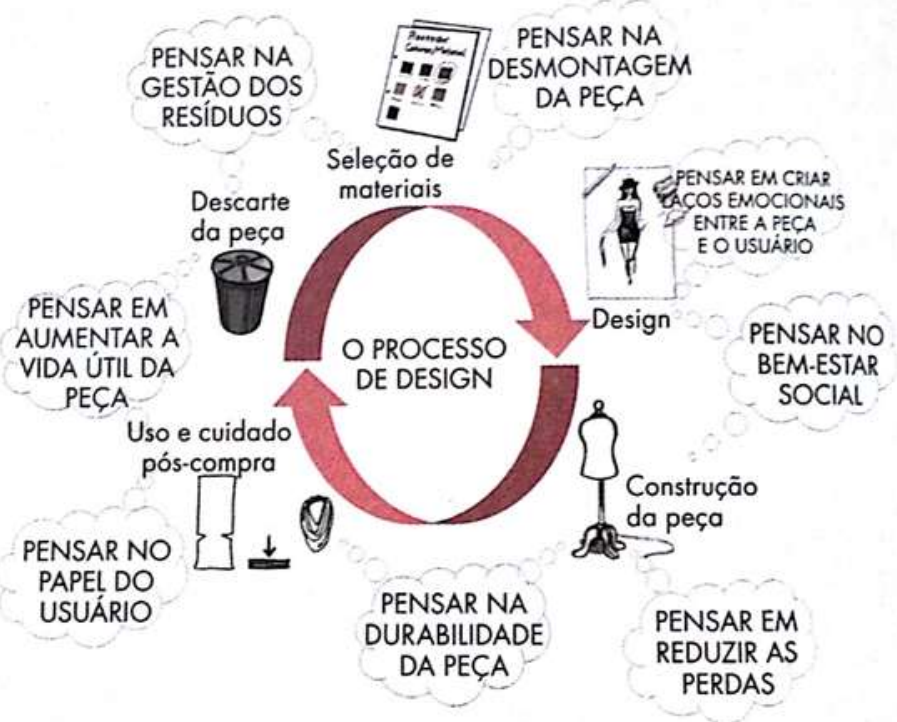

Fonte: SALCEDO (2014, p. 40).

No conceito de moda sob a perspectiva sustentável, toda a cadeia de valor tem seu papel, devendo assumir compromissos e responsabilidades compartilhadas para que o produto de moda cumpra o ciclo de vida para o qual foi desenvolvido, considerando um correto descarte quando não houver mais alternativas de reutilização.

\section{Procedimentos metodológicos}

A metodologia de pesquisa tem como natureza o método exploratório e descritivo e como delineamento o estudo de caso. Segundo Yin (2001) o estudo de caso permite uma investigação abrangente e significativa da vida real. Cooper e Schindler (2011) afirmam que o estudo de caso é uma combinação de análise de registros e observações permitindo a realização de entrevistas individuais. Os autores ainda contemplam a possibilidade de se entender o significado que as pessoas atribuem às suas experiências por meio das quais o pesquisador pode compreender os acontecimentos com abordagens qualitativas. A pesquisa bibliográfica, conforme Lakatos e Marconi (2003) é uma fonte secundária abrangendo a bibliografia tornada pública, deixando o pesquisador em contato com o que já foi estudado.

A presente pesquisa iniciou-se pela busca de bibliografias que abordam malharia retilínea, sustentabilidade e resíduos sólidos têxteis. A partir da composição do referencial bibliográfico foi possível identificar que as máquinas retilíneas eletrônicas permitem a 
redução da quantidade de resíduos sólidos têxteis gerados durante o processo de produção, pois eliminam um processo que é o corte da peça.

Ao serem analisados os dados do setor e os estudos realizados até o presente momento, conclui-se que ainda há muitos teares manuais com alta geração de resíduos sólidos dentro do parque fabril. São excedentes de fios nos conicais e rejeitos provenientes dos processos de corte.

Pergunta-se: Quais são as aplicações para os excedentes nos cones e o que fazer para diminuir a geração de resíduos do corte? O estudo de caso em questão procura alternativas para o uso dos excedentes de resíduos sólidos e técnicas de design para a não geração. Foram feitas entrevistas e visitas in loco em uma empresa localizada na grande São Paulo que atua há anos nesse segmento, com teares manuais e semiautomáticos.

As técnicas utilizadas pela empresa são as mais diversas, tanto para criar quanto para personalizar os produtos.

A malharia retilínea permite trabalhar com materiais e fios incomuns e criar novas padronagens. Com o passar do tempo e em consequência dos avanços, tornou-se permitido ao designer a exploração das mais diversas formas e comportamentos do tecido de malha trazendo, deste modo, inúmeras criações têxteis (SISSONS, 2012).

As técnicas utilizadas pela proprietária, que é formada em moda, são inúmeras, e sempre buscam o melhor aproveitamento da matéria prima e a incorporação do design como geração de valor visando a não geração e a diminuição dos resíduos sólidos, tanto no processo produtivo quanto depois da comercialização.

Para tanto, apresentar-se-á duas técnicas que visam a diminuição da geração dos resíduos sólidos, têxteis, sendo elas: upcycling e multiuso.

Upcycling dos excedentes de fios dos conicais do processo produtivo para a produção de novas peças

Os produtos apresentados foram construídos de forma artesanal como o uso, como matéria prima, de excedentes de fios originados de outros processos de personalização. Essa técnica permitiu a geração de valor, demandando tempo e criatividade do design e resultando em aumento do custo do produto acabado.

\section{Colete Policromático}


Para a produção foram tecidas tiras de tricô de diferentes larguras e comprimentos construídas na forma de flores alcançando volumes e texturas desiguais com a técnica da moulage. Foi montado um colete unindo-se as flores sem nova geração de resíduos. Esse processo consiste em projetar tiras com tamanhos predefinidos e montagem realizada manualmente. A figura 5 representa o fluxograma do método de produção do colete policromático.

Figura 5 - Fluxograma do processo produtivo do colete feminino

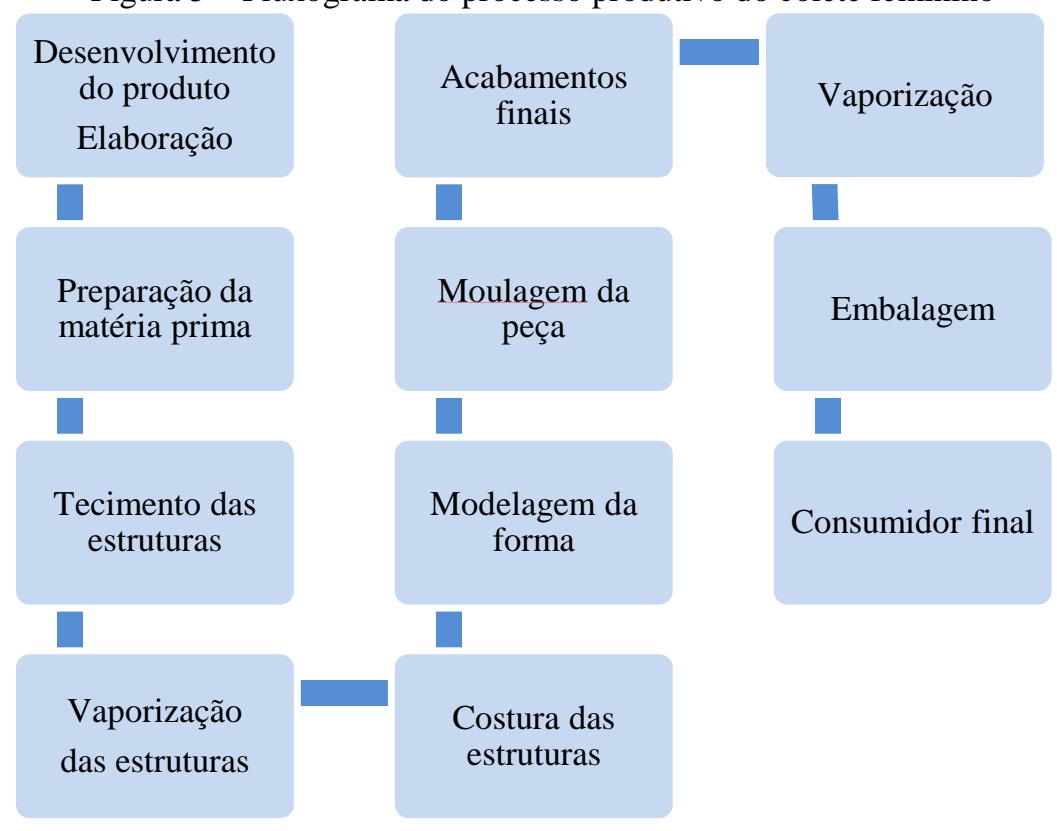

Fonte: Elaborado pelas autoras.

Para a confecção do colete os materiais selecionados foram: fios de composição 100\% acrílico e de título $\mathrm{Nm}$ 2/30, executado em 2 cabos em máquina manual de finura 10.

Produção das tiras:

1. Teceram-se tiras com estrutura de malha dupla;

2. Criou-se 56 tiras de $3 \mathrm{~cm}$ de largura com 11 agulhas por $40 \mathrm{~cm}$ de comprimento, sendo que: 06 azuis claros foram mescladas com azuis escuros, 05 pretas, 04 cinzas, 12 vermelhas rubi mescladas com azul escuro, 03 vermelhas rubi mescladas com coral, 14 vermelhas rubi mescladas com vermelho tomate e 12 vermelhas cereja;

3. Vaporização: Utilizou-se a vaporização para o fio se acomodar. 


\section{Montagem e costura:}

1. Iniciou-se a montagem costurando-se uma flor a outra obtendo-se o contorno desejado como na figura 6.a.b.c;

2. Moldou-se de maneira diferente para o contorno do pescoço como na figura 7.a; nas costas, como mostra a figura 6.c, sendo construída com uma única coluna de flores;

3. Montou-se uma flor diferenciada para o fechamento na parte da frente como mostra a figura $7 . b$;

4. E finalizou-se todas as flores com o miolo em pérolas de cores variadas como na figura 7.c, proporcionando um brilho no visual da peça.

Figura 6 - Colete policromático

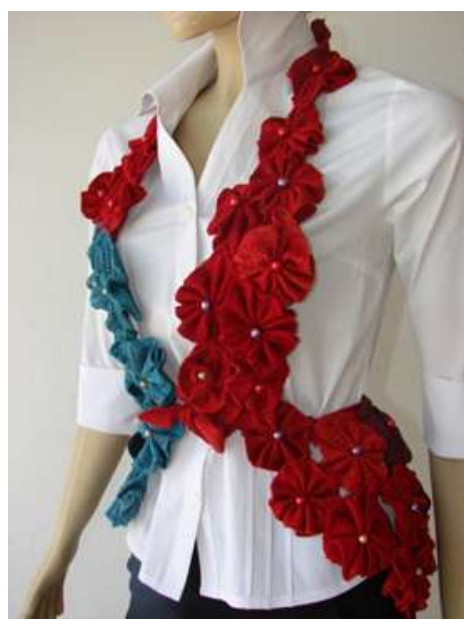

a) Frente do colete

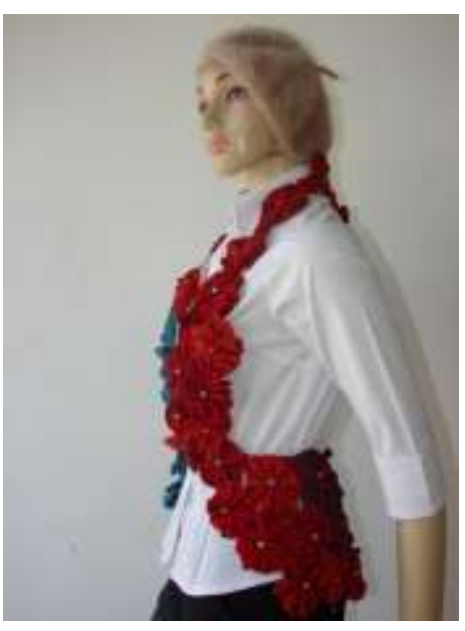

b) Lateral do colete

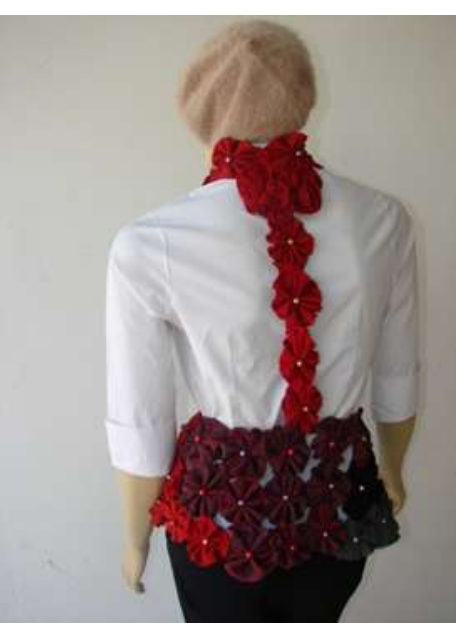

c) Costas do colete, composta por flores mescladas

Fonte: Autoras 
Figura 7 - Detalhamento das flores

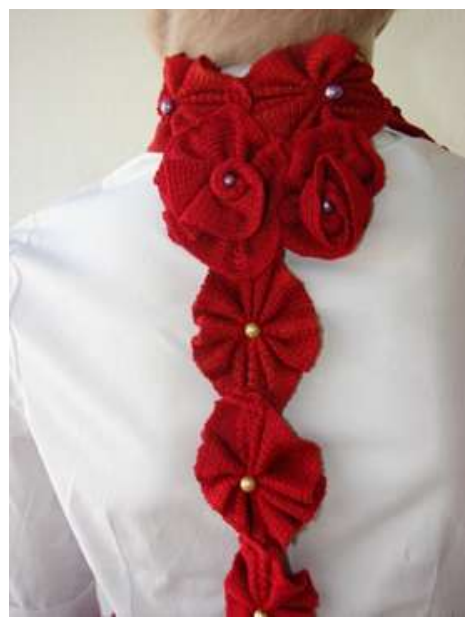

a) Detalhe contorno da gola com flor moldada de forma diferenciada.

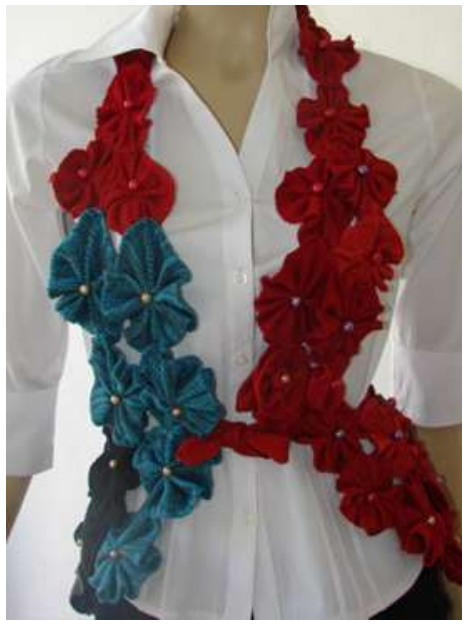

b) Pérolas coloridas compõe o miolo da flor

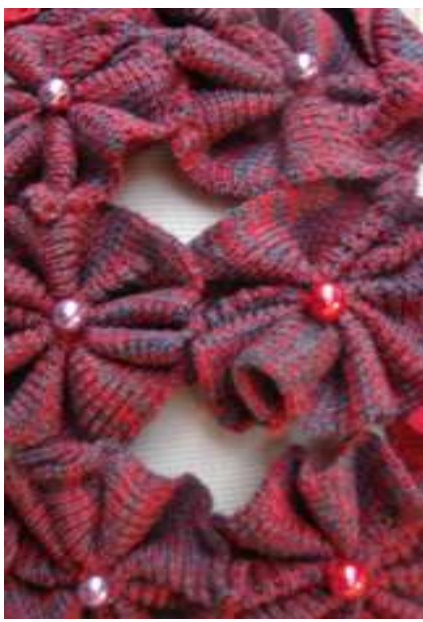

c) Flor mesclada em azul escuro com vermelho

Fonte: Autoras

\section{Conjunto de acessórios}

Para a preparação de todos os acessórios utilizaram-se, como matéria-prima, fios de composição $100 \%$ acrílico, título $\mathrm{Nm} 2 / 30$ e fios $100 \%$ viscose 33 TEX, conforme mostra a figura 8, executados em 2 cabos no tear em uma máquina manual de finura 10. 
Figura 8 - Matéria-prima utilizada para composição dos acessórios

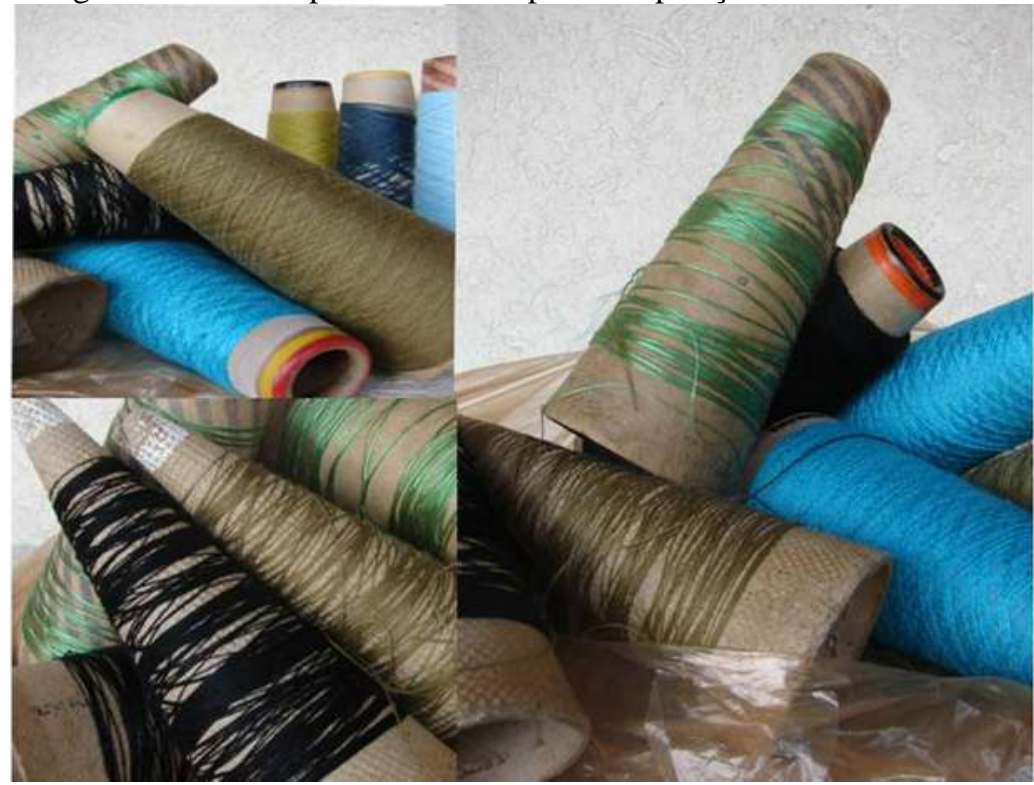

Fonte: Autoras.

O processo produtivo consiste na criação das peças, passando a ser concretizada pelo processo de tecelagem, montagem e modelagem, conforme mostra a figura 9.

Figura 9 - Fluxograma do processo de produção dos acessórios

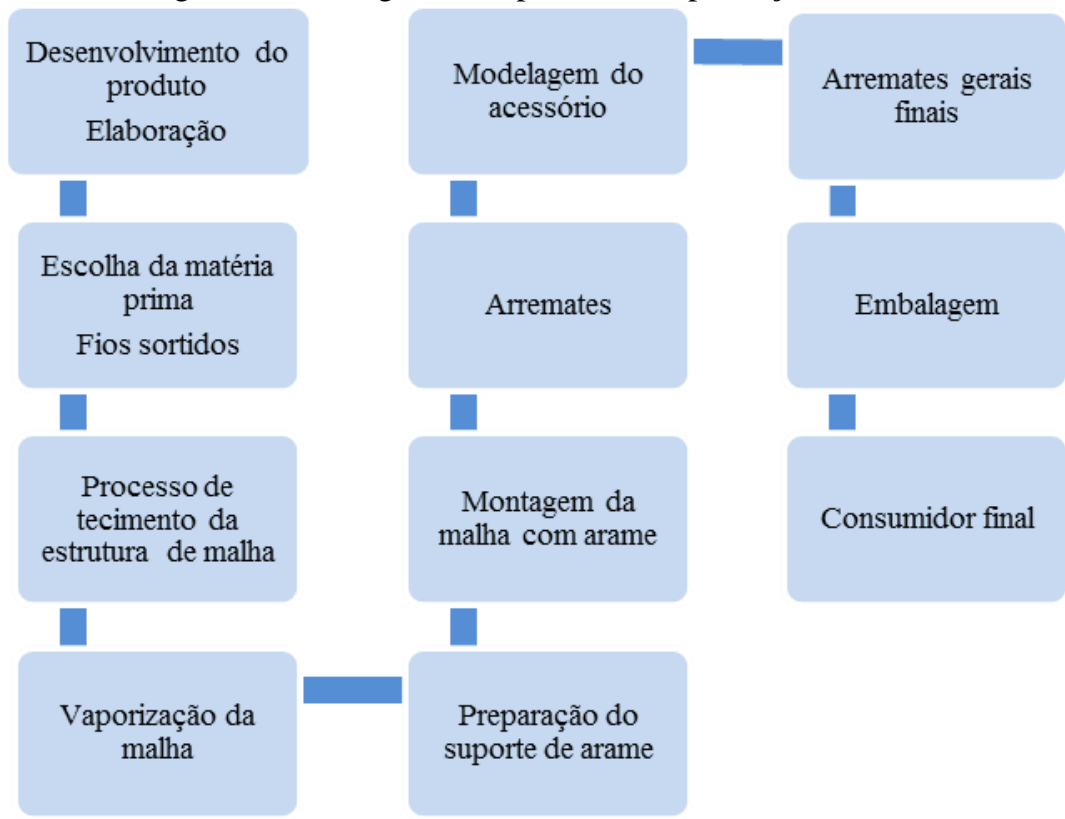

Fonte: Autoras 


\section{Conjunto Preto}

Nesse primeiro conjunto foi utilizada uma única cor para o desenvolvimento do acessório de estrutura tubular.

Para a produção utilizou-se:

1. 3 tubulares para o contorno com $0,80 \mathrm{~m}$ de comprimento e 4 agulhas de diâmetro;

2. 2 tubulares para a parte central, sendo 1 com $1,50 \mathrm{~m}$ e o outro de $2 \mathrm{~m}$ de comprimento com 5 agulhas de diâmetro.

3. Para o anel foi necessário um único tubular com $1 \mathrm{~m}$ de comprimento e 3 agulhas de diâmetro.

4. O bracelete se constituiu de um único tubular de $2 \mathrm{~m}$ de comprimento e 4 agulhas de diâmetro.

5. Para as estruturas arame galvanizado.

\section{Montagem e costura:}

1. Iniciou-se a montagem modelando-se manualmente o formato espiral desejado. Neste caso foram produzidas pequenas laçadas em tamanhos distintos. Em seguida foram costuradas as partes do colar, obtendo-se os acessórios conforme na figura 10. 
Figura 10 - Maxi colar, bracelete e maxi anel modelados em forma espiral
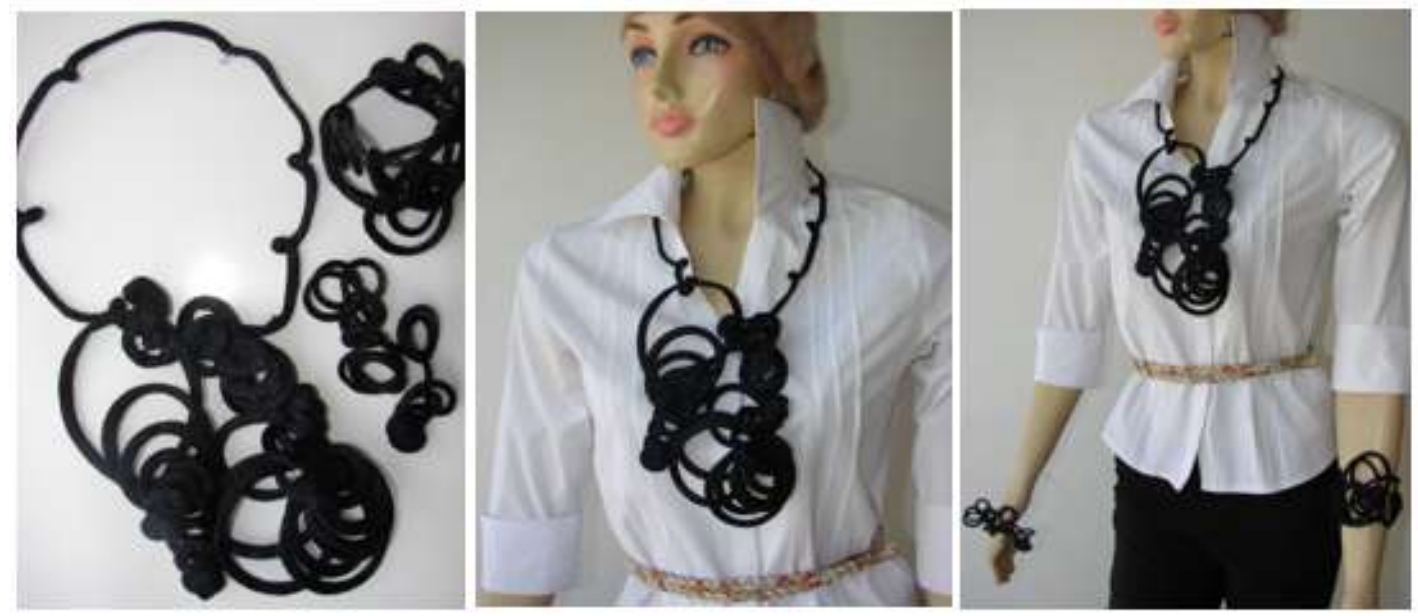

Fonte: Autoras.

\section{Conjunto Multicolorido}

Nesse conjunto, para o desenvolvimento do acessório, foram abordadas quatro cores distintas, sendo elas: azul, preto, verde e prata, evidenciando o maior aproveitamento das matérias-primas.

\section{Para a produção utilizou-se:}

1. Para o colar: 4 tubulares de cores diferentes: azul, prata, preto e verde, sendo que, para as cores azul, prata e preto foi utilizado um tubular de $1,50 \mathrm{~m}$ de comprimento e 4 agulhas de diâmetro e para o verde, um tubular de $2 \mathrm{~m}$ de comprimento e 4 agulhas de diâmetro;

2. Na construção do bracelete: para as cores azul, prata e verde foi utilizado um tubular em cada cor composto de $1 \mathrm{~m}$ de comprimento e 4 agulhas de diâmetro, enquanto o preto construiu-se com $0,80 \mathrm{~m}$ de comprimento e 4 agulhas de diâmetro;

3. Para o anel foram utilizados dois tubulares, verde e prata, com $0,80 \mathrm{~m}$ de comprimento e 4 agulhas de diâmetro; dois tubulares preto e um azul de $0,10 \mathrm{~m}$ de comprimento e 4 agulhas de diâmetro cada.

\section{Montagem e costura:}


1. Iniciou-se a montagem modelando-se manualmente o formato desejado manuseando ao mesmo tempo quatro tiras de tubulares, obtendo-se o acessório e finalizando-os por costuras.

$\mathrm{Na}$ realização deste conjunto de acessórios observou-se um maior cuidado e dificuldade na etapa da modelagem, pois foram unidos quatro tubulares ao mesmo tempo, modelando-os, afim de alcançar o formato desejado. O processo exigiu um esforço manual para favorecer o acessório conferindo uma característica inovadora, como mostra a figura 11.

Figura 11 - Conjunto de acessórios multicolorido composto por maxi anel, bracelete e colar
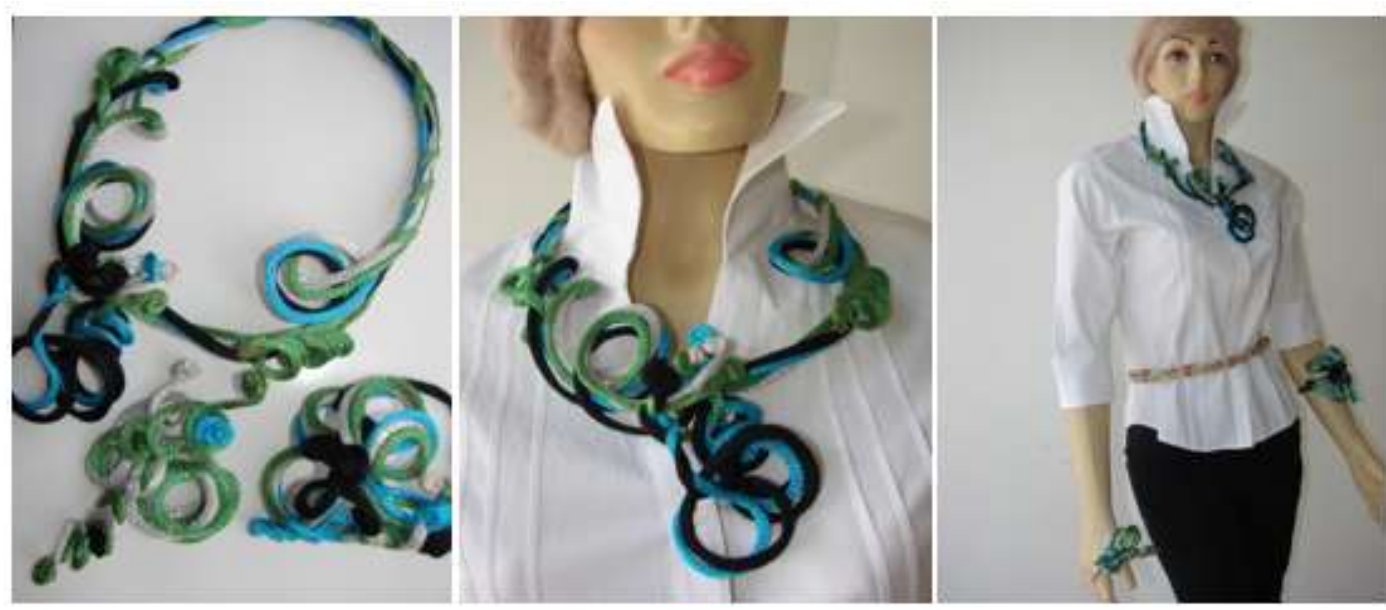

Fonte: Autoras.

\section{Técnica de design multiuso}

A peça com possibilidade de multiuso apresenta um conhecimento muito amplo e extensivo do design em relação às questões de técnica de construção da vestimenta. Foram visualizados ângulos, proporções e uniões improváveis dentro do designer e da modelagem, além das possibilidades de adaptação de conceitos ao produto, fazendo com que fosse aceito e usado de formas criativas pelo consumidor. Oferecem tratamento em relação à inércia com inúmeros níveis de envolvimento, elaborando uma ligação forte e duradoura entre o consumidor e o produto, prolongando sua usabilidade (FLETCHER; GROSE, 2011).

É importante que o consumidor conheça as várias funcionalidades e multiusos do artigo. Fletcher e Grose (2011) afirmam que deve haver uma ponderação de funcionalidade, pois o excesso pode criar confusão para o consumidor final, proporcionando o uso em suas funções básicas e raramente nas outras possibilidades. 


\section{Yellow Coat}

Os tecidos utilizados foram produzidos com fios de composição $50 \%$ algodão e $50 \%$ acrílico, produzidos em maquinário de malharia retilínea manual de finura 10. A figura 12 , representa o fluxograma do processo produtivo.

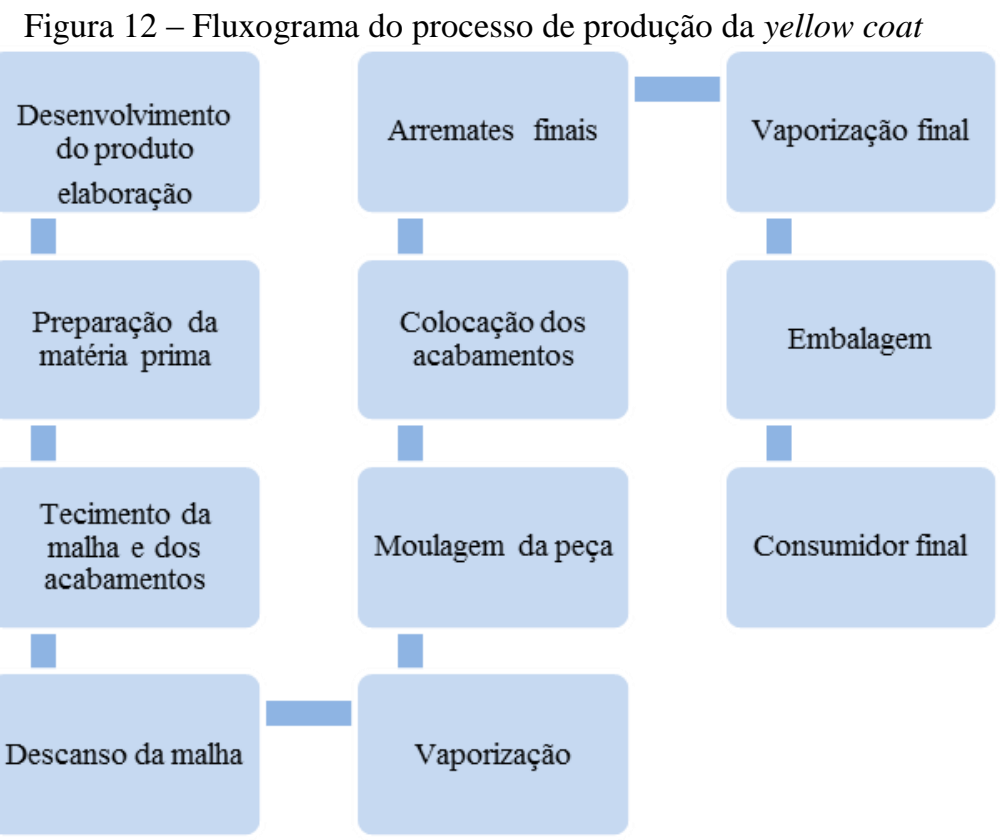

Fonte: Autoras

Produção:

1. Construiu-se dois tecidos, um para o detalhamento e outro para o corpo. $\mathrm{O}$ tecido para detalhamento foi de aproximadamente $0,80 \mathrm{~m}$ de largura por 0,60 $\mathrm{m}$ de comprimento. Para o corpo, um tecido de $0,90 \mathrm{~m}$ de largura por $0,70 \mathrm{~m}$ de comprimento, destacando-se, na sua realização, a não geração de resíduos, pois é construída sem sobras de tecido.

Montagem e costura:

1. A montagem surgiu por meio da sobreposição do tecido sobre o corpo de um manequim dando início aos estudos das formas diferenciadas. Dois tecidos costurados de forma estratégica e sem recortes apresentaram duas formas visuais diferentes a serem exploradas. 
2. Na primeira peça (figura 13) aconteceu a formação de uma gola ampla e estruturada que é fechada com uma amarração central. Caso a peça seja invertida, a gola estruturada (figura 14) passa a ser o barrado da capa, oferecendo a esta uma abertura frontal e comprimento totalmente diferentes.

Figura 13 - Capa com gola fechada frente, lateral e costas
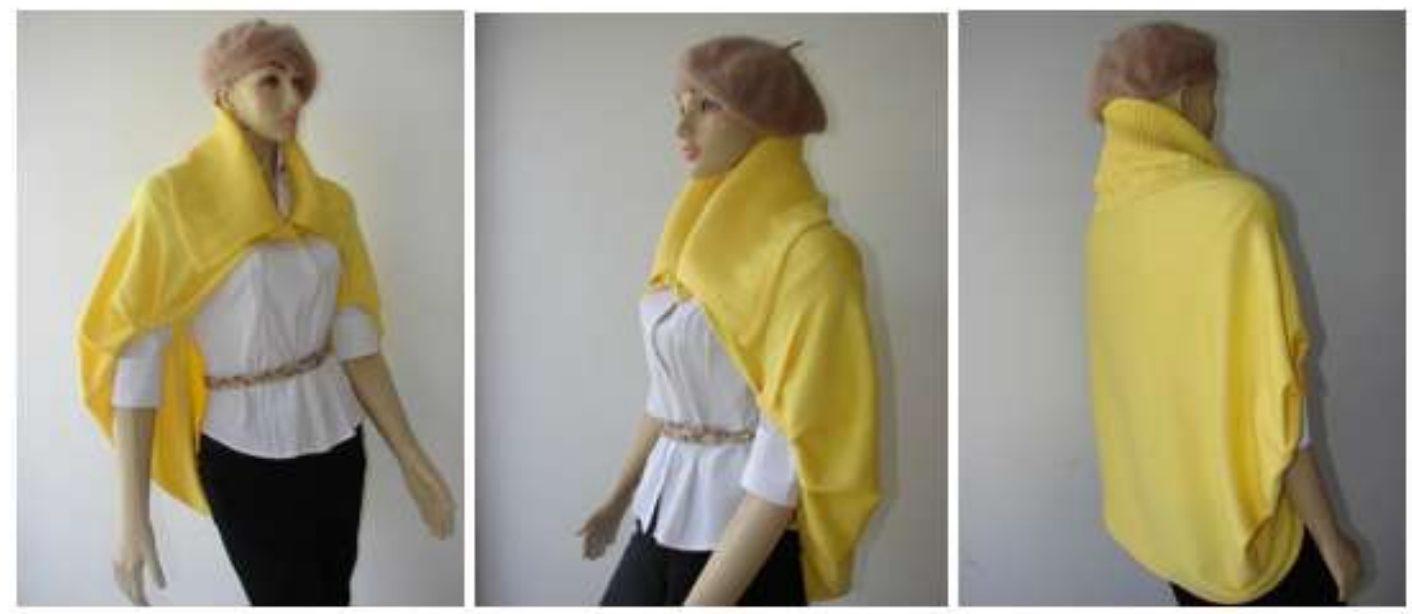

Fonte: Autoras

Figura 14 - Sobreveste Frente, lateral e costas

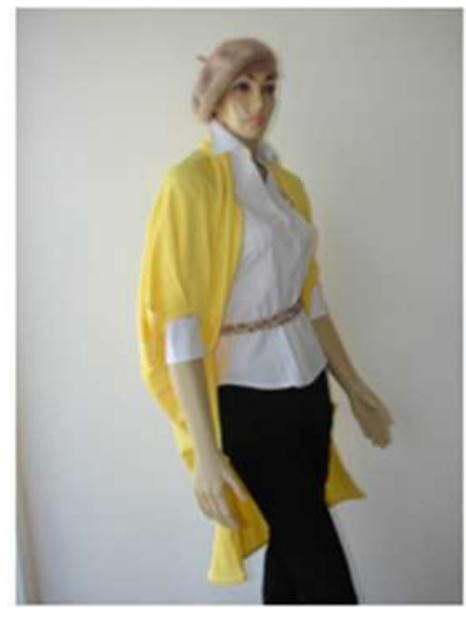

\section{Considerações Finais}

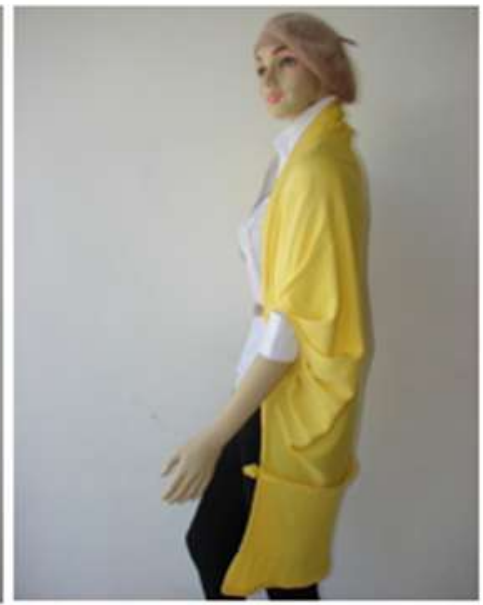

Fonte: Autoras
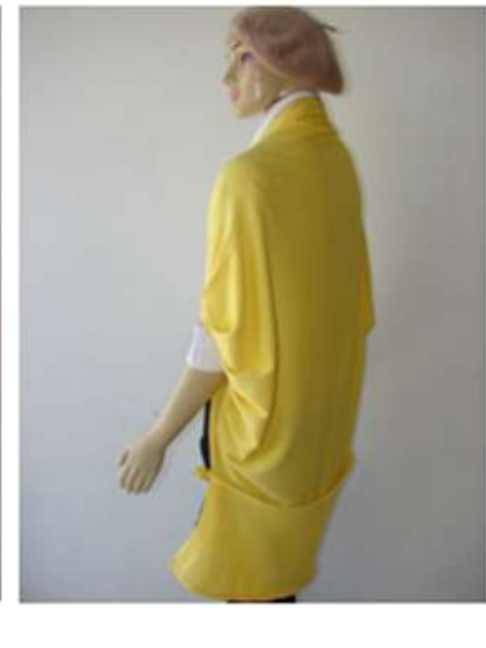

A indústria têxtil está entre as maiores poluidoras do ar, solo e água. Porém, grandes ações e atitudes devem ser tomadas para mudar esse cenário. 
As máquinas de malharia retilínea automáticas permitem a criação de peças semiacabadas, possuindo alto grau de versatilidade, reduzindo a geração de resíduos sólidos durante o processo de fabricação.

Os fatores que favorecem o desenvolvimento de um produto podem ser muito bem supridos na malharia, técnica que oferece as ferramentas necessárias para o desenvolvimento criativo incluindo suas características próprias do fio utilizado e da construção do tecido propiciando maior respirabilidade, elasticidades e praticidade.

Pode-se constatar que a realização dos processos de construção da peça multiuso juntamente com a criatividade do cliente final resultam em um produto que adquire caráter específico, podendo ser manipulado em vertentes diferentes que estimulam o seu uso em ocasiões diversificadas, conforme a capacidade criadora do consumidor.

É crescente as manifestações de design buscando a geração de novos itens, pensando em minimizar a utilização de matéria prima destinando a este um caráter inovador. A técnica upcycling pode resultar em itens inovadores otimizando matéria prima e recriando artigos novos por meio de itens que seriam lançados no lixo.

No estudo de caso apresentado foi possível observar a redução dos resíduos sólidos por meio de técnicas do design, porém permanece como sugestão a substituição da matéria prima utilizada por fios constituídos de monofibras que facilitam a reciclagem no fim de vida com grande contribuição ambiental.

Nesse contexto pode-se concluir que empresas que focam em sustentabilidade estão cada vez mais investindo em ideias, processos, produtos, design, entre outros, que ao mesmo tempo em que diminuem os impactos das atividades, promovem a conscientização e auferem lucros. No entanto, no setor da moda, ainda há carência de estudos científicos que apresentem novos modelos de negócios e possibilidades técnicas a serem utilizadas. Há a necessidade de novos estudos com o engajamento de maior número de empresas para que a visão não se constitua unilateralmente. 


\section{REFERÊNCIAS}

ABRAMOVAY, R. Responsabilidade Socioambiental: as empresas no meio ambiente, o meio ambiente nas empresas. In: VEIGA, J. E. Economia Socioambiental. São Paulo: Senac, 2009. p. 337-358.

ANICET, A., FELIPPI, V., RUTHSHILLING, E., TOMAZZONI, R. Upcycling de fios de malharia retilínea em produtos de moda sustentável. $2^{\circ}$ CIMODE, 2014.

AZZONE, G.; BERTELÈ, U.; NOCI, G. At last we are creating environmental strategies which work. Long Range Planning, v. 30, n. 4, 1997.

BERLIM, L. Moda e sustentabilidade: uma reflexão necessária. São Paulo. Estação das letras e cores, 2012.

COSTA, A. C. R.; ROCHA, E. R. P. Panorama da cadeia produtiva têxtil e de confecção e a questão da inovação. BNDES Setorial, Rio de Janeiro, n. 29, p. 159-202. 2009.

CAllan, G. O. Enciclopédia da Moda. São Paulo: Companhia das Letras, 2010.

COOPER D., SCHINDLER P. S. Métodos de pesquisa em administração. Porto Alegre: Bookman, 2011.

DIAS, R. Eco-inovação: caminho para o crescimento sustentável. São Paulo. Atlas, 2014.

ESTADO DE AMAZONAS. Superintendência da Zona Franca de Manaus. Inventário anual de resíduos sólidos industriais 2012. Relatório dez. 2012. 24 p.

FLETCHER, K., GROSE, L. Moda \& Sustentabilidade: Design para mudança. São Paulo. SENAC, 2011.

GWILT, A. Moda Sustentável: Um guia prático. São Paulo: Gustavo Gili, 2014. Tradução: Márcia Longarço.

HART, S.; MILSTEIN, M. Criando Valor Sustentável. RAE Executivo, v. 3, n. 7, p. 65-79, maio/junho 2004.

IEMI. Instituto de Estudos e Marketing Industrial. Relatório Setorial da Cadeia Têxtil Brasileira. São Paulo: Free Press, 2014.

IPEA. Instituto de Pesquisa Econômica Aplicada. Diagnóstico sobre Resíduos Industriais. Relatório de Pesquisa. Brasília: Ipea, 2012.

JONES, SJ. Fashion designer - manual do estilista. São Paulo: Cosac Naify, 2005.

LAKATOS, E. M.; MARCONI, M. A. Fundamentos da Metodologia Científica. São Paulo: Atlas, 2003. 310 p.

LOPES, G. B. Práticas do Gerenciamento de Resíduos nas Indústrias de Confecções da Região da Rua Teresa - Petrópolis. 2013.98 f. Dissertação 
(Mestrado) - Curso de Programa de Engenharia Ambiental, Universidade Federal do Rio de Janeiro, Rio de Janeiro, 2013.

MENDES, F. D.; SACOMANO, J.; FUSCO J. Redes de empresas: a cadeia têxtil e as estratégias de manufatura na indústria brasileira do vestuário de moda. $1^{\circ} \mathrm{ed}$.São Paulo: Arte e ciência, 2010.

MILAN, G. S. REIS, Z. C. VITORAZZI, Camila. A redução de resíduos têxteis e de impactos ambientais: Um estudo desenvolvido em uma indústria de confecções do vestuário. XIII SEMEAD, 2010.

MORO, R. C. L.; MENDES, F. D. As estratégias de terceirização da mvm e suas consequências sociais: estudos de casos. In: ENCONTRO NACIONAL DE ENGENHARIA DE PRODUCAO, 34. 2014, Curitiba. Anais... Curitiba: Abepro, 2014.

PICCININI, L.; MENDES, F.D. O Estudo da Sustentabilidade no Processo Produtivo de Moda na Malharia Retilínea. In: 4O. ENPModa - Encontro Nacional de Pesquisa em Moda, 2014, Florianopolis - SC. 4o. ENPModa - Encontro Nacional de Pesquisa em Moda, 2014.

PINSKY, V. C.; DIAS, J. L. Sustentabilidade e Inovação em Bens de Consumo. In: KRUGLIANSKAS, Isak; PINSKY, Vanessa Cuzziol (Org.). Gestão Estratégica da Sustentabilidade: Experiências Brasileiras. São Paulo: Elsevier, 2014. p. 175-210.

PORTER, M.; LINDE, C. Verde e Competitivo: Superando o Impasse. 1995. In: PORTER, M. Competição. Rio de Janeiro: Elsevier, 2009. p. 349-374.

ROOS, D. B. Bretz. O setor industrial de malharia retilínea de Caxias do Sul: um estudo sobre o aglomerado de pequenas empresas. 2001. 117 f. Dissertação (Mestrado) - Curso de Programa Ciências Econômicas, Universidade Federal do Rio Grande do Sul, Porto Alegre, 2009.

SALCEDO, E. Moda ética para um futuro sustentável. Barcelona: Gustavo Gili, 2014. Tradução: Denis Fracolossi.

SINDITÊXTIL SP - Sindicato das Indústrias de Fiação e Tecelagem do Estado de São Paulo - <http://www.sinditextilsp.org.br/\#sthash.fOw6AQmV.dpuf> Acesso em: $15 / 10 / 2014$.

SILVA, A. C. C.; LEITÃO, M. P.; LEMOS, P. I. Embalagem e informação: A importância da informação ambiental nos debates para gestão sustentável de resíduos no Brasil. In: SANTOS, Maria Cecilia Loschiavo dos (Comp.). Design, Resíduo \& Dignidade. São Paulo: Olhares, 2014. p. 185-201.

SISSONS, J. Fundamentos de design de moda: Malharia. Tradução técnica: Bruna Pacheco. Porto Alegre: Bookman, 2012.

YIN, R. K. Estudo de caso: planejamento e métodos trad. Daniel Grassi - 2.ed. -Porto Alegre: Bookman, 2001.

TORRES, V.; BORGER, G. Política Nacional de Resíduos Sólidos e seus Desafios para a Indústria de Eletroeletrônicos: Estudo de Caso Hewlett Packard Brasil. In: 
KRUGLIANSKAS, I.; PINSKY, V. C. (Org.). Gestão Estratégica da

Sustentabilidade: Experiências Brasileiras. São Paulo: Elsevier, 2014. p. 149-171. 